\title{
Differentiated thyroid cancer in patients with resistance to thyroid hormone syndrome. A novel case and a review of the literature
}

\section{João Vinagre ${ }^{1,2}$, Fátima Borges ${ }^{3}$, António Costa $^{4}$, Maria Inês Alvelos ${ }^{1}$, Glaúcia Mazeto ${ }^{5}$, Manuel Sobrinho-Simões ${ }^{1,6,7}$ and Paula Soares ${ }^{1,6 *}$}

\author{
1 Institute of Molecular Pathology and Immunology of the University of Porto, Porto, Portugal \\ 2 Institute of Biomedical Sciences Abel Salazar (ICBAS), Porto, Portugal \\ ${ }^{3}$ Department of Endocrinology, Diabetes and Metabolism, Centro Hospitalar do Porto, Porto, Portugal \\ ${ }^{4}$ Department of Surgery 2, Centro Hospitalar do Porto, Porto, Portugal \\ ${ }^{5}$ Hospital das Clínicas de Botucatu, São Paulo, Brazil \\ ${ }^{6}$ Medical Faculty of the University of Porto, Porto, Portugal \\ 7 Department of Pathology, Centro Hospitalar São João, Porto, Portugal
}

\section{Edited by:}

Arun Bhardwaj, University of South Alabama Mitchell Cancer Institute, USA

\section{Reviewed by:}

Nikhil Tyagi, University of South Alabama Mitchell Cancer Institute, USA

Kaushlendra Tripathi, University of South Alabama Mitchell Cancer Institute, USA

\section{*Correspondence:}

Paula Soares, Institute of Molecular Pathology and Immunology of the University of Porto, Rua Dr. Roberto Frias, s/n, 4200-465, Porto, Portugal e-mail: psoares@ipatimup.pt
Resistance to thyroid hormone (RTH) represents a syndrome in which patients present elevated circulating thyroid hormones in the presence of non-suppressed TSH. We report a novel case where a patient with RTH presented a differentiated thyroid cancer. A19 year-old female had been referred due to thyroid disease that disclosed features characteristic of a RTH. During the follow up it was detected a follicular tumor that led to the recommendation for thyroid surgical ablation, where an incidental papillary thyroid microcarcinoma (mPTC) was found. The increase of thyroglobulin (TG) levels following thyroid removal referred the patient for radioiodine treatment. Post-treatment, it was detected jugular adenopathies and the patient was subjected to cervical lymph node drainage where metastases of the MPTC were found. RTH syndrome was confirmed by the detection of a THRB germline mutation. A BRAF mutation was also found in the mPTC but not detected in the follicular adenoma or normal adjacent tissue. The young age of the patient, the rarity of BRAF mutations in childhood and the high dissemination of the malignancy, lead us to the speculation that increased TSH stimulation in a RTH background and oncogenic activation of BRAF could have served as (co) drivers and might have triggered an advanced stage of the neoplastic disease. These findings together with a review of published cases add novel information to the management of RTH patients with differentiated thyroid cancer.

Keywords: resistance to thyroid hormone, thyroid cancer, MPTC, THRB, BRAF

\section{INTRODUCTION}

Thyroid hormone receptors (TRs) belong to the nuclear receptor superfamily that regulates the activity of thyroid hormone, triiodothyronine $\left(\mathrm{T}_{3}\right)$, responsible for growth, differentiation and metabolism. The $\mathrm{T}_{3}$-binding receptors are presented in four major isoforms: TR $\alpha 1$, TR $\beta 1, \operatorname{TR} \beta 2$, and TR $\beta 3$. These receptors are codified by THRA and THRB genes present on chromosomes 17 and 3, respectively (Yen, 2001). TRs are able to bind to specific DNA motifs on the promoters of $T_{3}$-target genes, thyroid hormone responsive elements (TREs), leading to its transcription activation or repression (Guigon and Cheng, 2009).

Mutations in THRB gene lead to a decreased tissue responsiveness to thyroid hormones and cause Resistance to thyroid hormone (RTH) syndrome. Most mutations cluster in a hotspot area encoding the $\mathrm{T}_{3}$-binding domain that spans exons $8-10$ (Yen, 2001). However, a RTH phenotype can also manifest in absence of THRB alterations (Beck-Peccoz et al., 2006). The disease is normally inherited in an autosomal dominant manner, and the mutant receptors usually exert a dominant negative activity over the wild-type receptors interfering with receptor dimerization and binding to TREs (Guigon and Cheng, 2009). Clinically, the hallmark of RTH patients is the presence of high levels of free thyroid hormones in the presence of measurable TSH. The clinical phenotype of these patients is variable with most patients presenting mild to moderate symptoms, but the most common finding is the presence of goiter (Refetoff and Dumitrescu, 2007).

In the last years, a few cases of RTH and differentiated thyroid cancer have been reported (Taniyama et al., 2001; Kim et al., 2010; Paragliola et al., 2011; Ramos-Prol et al., 2013; Unluturk et al., 2013). We present a novel case in which mPTC was associated with a THRB germline mutation. Due to the unexpected progression of the mPTC we decided to investigate further the case looking for molecular alterations relevant for the development, in this particular case, of a metastatic disease. 


\section{MATERIALS AND METHODS INFORMED CONSENT}

All procedures followed were in accordance with the national ethical standards previously approved by Local Ethical Review Committees. Informed consent was obtained from the patient for being included in the study.

\section{CASE REPORT}

In late 1999, a 19-year-old female was referred to the Endocrinology Department due to thyroid disease. On physical examination, she presented goiter, a heart rate of 80 beats per min, no Graves' ophthalmopathy and no hand tremor although it was observed palmar hyperhidrosis. The patient had no signs of emotional disturbances, learning disabilities or mental retardation, though it was noticeable a hyperactive behavior. Clinical measurements (Figure 1) revealed out of range levels of circulating free thyroxine $\left(\mathrm{T}_{4}\right)(2.87 \eta \mathrm{g} / \mathrm{dL}$, normal range $0.89-$ $1.76 \eta \mathrm{g} / \mathrm{dL})$ and free triiodothyronine $\mathrm{T}_{3}(5.3 \rho \mathrm{g} / \mathrm{mL}$, normal range $2.0-4.2 \rho \mathrm{g} / \mathrm{mL}$ ) with the presence of non-suppressed TSH $(1.188 \mu \mathrm{UI} / \mathrm{mL}$, normal range $0.4-4.4 \mu \mathrm{UI} / \mathrm{mL})$. Antithyroid antibodies were also measured and were at non-detectable levels discarding thyroid autoimmune disease. The patient had been prescribed with antithyroid therapy (thiamazole $10 \mathrm{mg}$ per day orally) to control the mild hyperthyroidism. Novel evaluation presented once more abnormal high levels of free $\mathrm{T}_{3}$ and $\mathrm{T}_{4}$ in the presence of TSH. These results pointed to a case of central hyperthyroidism. To exclude the presence of a pituitary adenoma, the patient was subjected to a CT scan and $\alpha$-GSU was assayed. The coronal CT scan revealed a normal gland without focal hypodensity or characteristics suggestive of a pituitary adenoma, and $\alpha$-GSU dosage was within normal levels. Taking all this into consideration a diagnosis of RTH was proposed.

RTH diagnosis was later (2008) confirmed by mutation analysis of the THRB gene that disclosed a germline missense mutation. Both parents were tested for the mutation and no alterations were detected indicating a de novo origin.

The patient was referred for monitoring and was followed on a regular basis. In mid 2003, it was noticeable a thyroid enlargement and palpation exam of the thyroid gland indicated the presence of solid nodules. Ultrasound imaging confirmed solid, well circumscribed nodules on the left lobe and a smaller one on the right side. Fine needle aspiration biopsy (FNAB) of the nodules indicated follicular tumor(s) and the patient was recommended for total thyroidectomy. Surgical thyroid ablation was performed in May 2004. Histological examination of the left lobe revealed the presence of follicular patterned nodules, the biggest one, a fetal follicular adenoma with $15 \mathrm{~mm}$ (Figure 2A). The right lobe presented a $4 \mathrm{~mm} \mathrm{mPTC}$ (Figure 2B). Post-surgical TSH level was $58 \mu \mathrm{UI} / \mathrm{mL}$, and the patient started replacement therapy with levothyroxine. The patient presented a body weight averaging $56 \mathrm{Kg}$, so it started to receive an initial dose of $0.1 \mathrm{mg} /$ day of levothyroxine $(\approx 1.7 \mu \mathrm{g} / \mathrm{Kg})$. The starting dose was based on the recommended dosage for management of hypothyroidism according to the American Thyroid Association (ATA) guidelines. Since RTH patients require higher doses of replacement hormone, medication was meant to be adjusted periodically (using the TSH as a guideline) in order to lower TSH levels and maintain normal levels of thyroid hormone. However, during the adjustment the patient started to present tremors, weight loss, irritability and sudation. These symptoms led to the decision of slowing the gradually introduction of supraphysiological

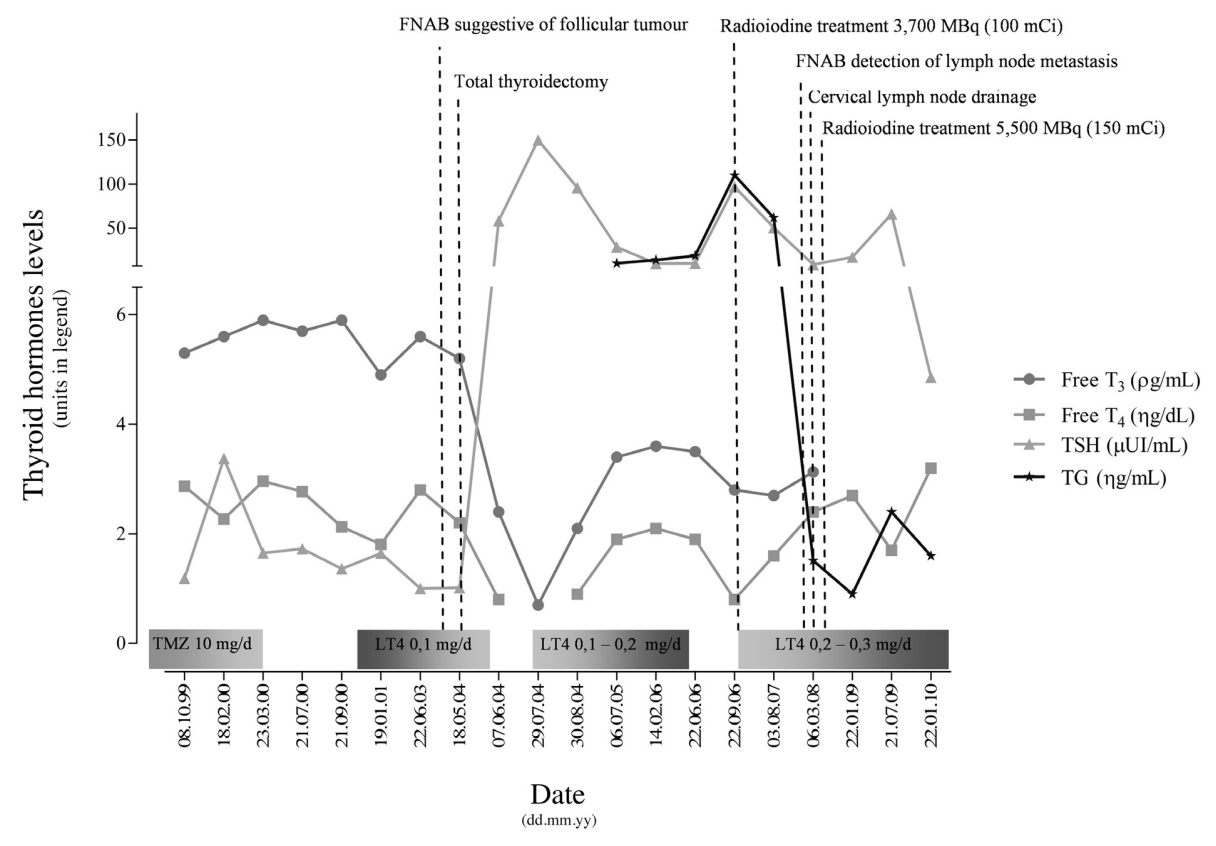

FIGURE 1 | Major events, clinical measurements and therapy management of the patient referring the period on first appearance until the last appointment. Abbreviations: TMZ, Thiamazole; LT4, Levothyroxine. 


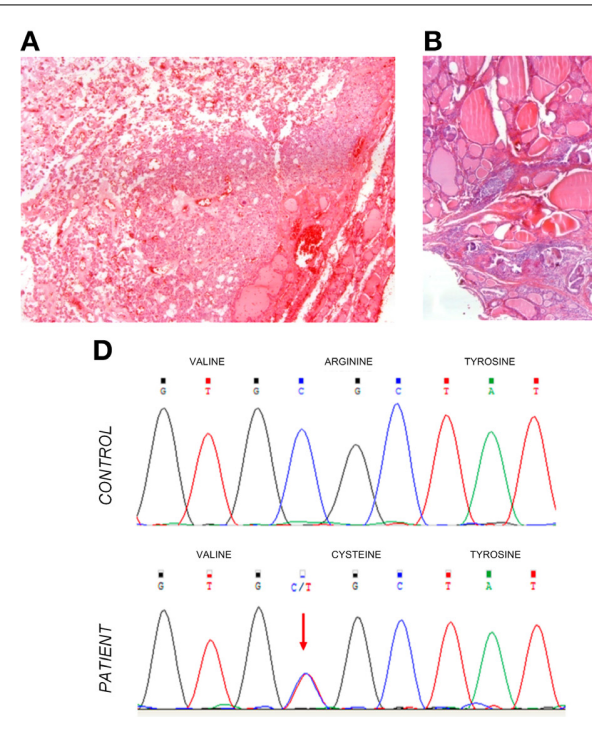

FIGURE 2 | Haematoxylin-eosin stained histological sections of a follicular adenoma, initially detected in the patient (A); a papillary microcarcinoma (B); and metastasis of the MPTC in a lymph node following the cervical drainage (C). The total magnification of the sections is 200X. Molecular genotyping of the samples detected the

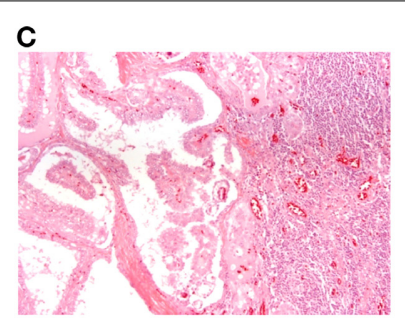

E

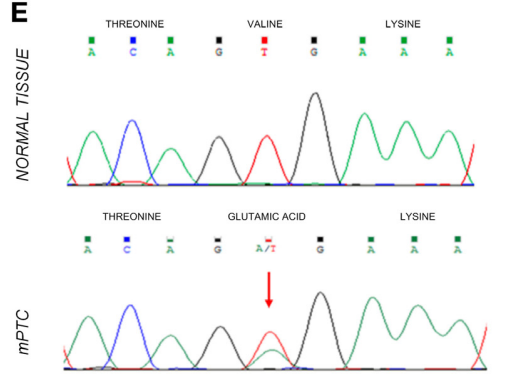

presence of a THRB germline mutation detected in DNA extracted from blood cells (D). Somatic mutation analysis disclosed the presence of a $B R A F$ V600E alteration in the MPTC (E, bottom sequence) whereas a wild-type BRAF sequence was present in the normal adjacent tissue (E, top sequence). doses for full replacement. Due to the mPTC incidental finding, thyroglobulin (TG) levels started to be checked. In 2006, TG levels were slowly increasing and the patient was submitted to radioiodine treatment $3700 \mathrm{MBq}(100 \mathrm{mCi})$. The patient remained under regular appointments for assessment and TG levels kept being monitored. During 2007, an imagiological study detected homolateral jugular adenopathies. Evaluation of FNAB cytologic slides revealed metastases of papillary thyroid carcinoma (PTC). The patient was subjected to cervical lymph node drainage. Histological examination found metastases of PTC in 7 out of 17 lymph nodes (Figure 2C). Another treatment with $5500 \mathrm{MBq}(150 \mathrm{mCi})$ was prescribed. Following the second treatment with radioiodine, TG values dropped to residual levels. In 2010, the patient appears to be free of metastatic disease, although treatment with levothyroxine is still implemented and has reached $0.3 \mathrm{mg} /$ day $(\approx 5.35 \mu \mathrm{g} / \mathrm{Kg})$ in order to control TSH levels. The previous symptoms presented by the patient were attenuated with the introduction of the beta-blocker, prescribed mainly to control tachycardia that started to manifest as a consequence of the levothyroxine dosage.

\section{THYROID ANTIBODIES AND HORMONE LEVELS OUANTIFICATION}

Measurements of thyroid autoantibodies were performed by radioimmunoassay (RIA) (Brahms Diagnostica, Hennigsdorf, Germany). The thyroid hormone levels were measured by electrochemiluminescence immunoassay (ECLIA) (Roche Diagnostic $\mathrm{GmbH}$, Mannheim, Germany). Both determinations were carried out according to the manufacturer specifications.

\section{GENETIC ANALYSIS}

Briefly, following whole blood DNA extraction, PCR amplification was performed and THRB gene was screened for mutations. Whole blood genomic DNA extraction was prepared using NucleoSpin Tissue Kit (Macherey-Nagel, Düren, Germany). Extraction of tumor and adjacent tissue DNA from paraffinembedded material was performed using the Invisorb spin tissue mini kit (Invitek, Berlin, Germany). Tumor and normal tissue samples were screened for TRHB BRAF, N and H-RAS and TERT promoter mutation. Amplifications were done using conditions described elsewhere (Trovisco et al., 2005; Rocha et al., 2007; Vinagre et al., 2013). PCR products were then purified and bidirectional sequenced on an ABI Prism $3130 x$ l Automatic sequencer (Perkin-Elmer, Foster City, USA) using the ABI Prism Dye Terminator Cycle sequencing kit (Perkin-Elmer).

\section{RESULTS}

Direct sequencing of THRB exon 9 showed a germline heterozygous mutation of a single base change in codon 320, Figure 2D. The mutation leads to an Arginine substitution by a Cysteine (R320C). The mutation found had been previously associated to a RTH case and functional characterization revealed that it induces a reduction of approximately $50 \%$ in $\mathrm{T}_{3}$ binding affinity (Burman et al., 1992). Additionally we screened the parents for the THRB mutation but it was not found, reflecting a de novo origin. Mutational analysis of BRAF (Figure 2E) in the mPTC and the lymph node metastasis revealed a Valine to Glutamic acid substitution at codon 600 (V600E). The BRAF mutation was not found in the normal adjacent tissue or in the follicular adenoma. No mutations were found in TERT promoter.

\section{DISCUSSION}

RTH corresponds to a syndrome of reduced responsiveness of the target tissues to thyroid hormone. Refetoff et al. initially described it in 1967 (Refetoff et al., 1967). In a daily practice, the main 
evidence of RTH still reflects the initial observations, presence of elevated levels of circulating free $\mathrm{T}_{4}$ and $\mathrm{T}_{3}$ along with normal or high levels of non-suppressed TSH (Beck-Peccoz et al., 2006). In the present case, the patient presented this trait, Figure 1, which pointed to a case of central hyperthyroidism, and RTH syndrome was thought to be the cause. Clinical manifestations of RTH can be very heterogeneous (Refetoff and Dumitrescu, 2007), among the most frequent symptoms of RTH the patient only exhibited, besides the abnormal hormonal levels, goiter and a hyperactivity disorder. In RTH the detection of parents and siblings with identical abnormal thyroid hormone and TSH levels were proposed by some authors as enough to provide the diagnosis. However, cases of RTH likely due to de novo mutations, as is the present case, have been identified in $28 \%$ of families with the condition (Refetoff and Dumitrescu, 2007).

With the identification of THRB gene mutations by Sakurai et al. (1989), the majority of the cases of RTH syndrome could be assigned to thyroid hormone nuclear receptor alterations. Nonetheless, $15 \%$ of individuals who present a RTH phenotype do not carry mutations in THRB gene. These are designated as "non-thyroid receptor RTH," and can present mutations in selenocysteine insertion sequence-binding protein 2 (SBP2) or in monocarboxylate transporter 8 (MCT8) genes (Refetoff and Dumitrescu, 2007). Our patient presented a "classic" RTH associated with a THRB mutation (R320C) that had been previously characterized and resulted in decreased $\mathrm{T}_{3}$ binding affinity (Burman et al., 1992), therefore confirming the advanced diagnosis. Since we found a mutation in THRB we did not screen SBP2 and MCT8 for mutations. The THRB mutations detected in RTH patients cluster mainly in the last 4 exons (7-10) that code for the hinge region and the $\mathrm{T}_{3}$ hormone ligand-binding domain of the receptor. These regions correspond to the carboxylterminus of the thyroid hormone receptor $\beta$. The majority of these mutations result in the modification of the ligand-binding domain site that does not allows the binding of the thyroid hormone and thus does not function as a proper receptor. Additionally to the reduction in $\mathrm{T}_{3}$-binding, it can also lead to impairment in transactivation.

Somatic mutations of THRB have been previously described in hepatocellular, renal cell carcinoma and other cancers but do not present a pivotal role in human thyroid carcinogenesis as we and others, were unable to detect THRB mutations in human follicular thyroid adenomas, PTC or FTC (Rocha et al., 2007; Ramos-Prol et al., 2013). Increased frequency of thyroid cancer was not commonly observed or was not reported in RTH patients. More recently, cases with thyroid cancer in RTH patients started to be reported and so far there are already 7 cases in the literature (Taniyama et al., 2001; Kim et al., 2010; Paragliola et al., 2011; Ramos-Prol et al., 2013; Unluturk et al., 2013); reviewed in Table 1. THRB mutations can lead to increased TSH levels

Table 1 | Review of known cases of RTH patients with differentiated thyroid cancer.

\begin{tabular}{|c|c|c|c|c|c|c|c|}
\hline References & Age & Gender & \multicolumn{3}{|c|}{ Tumor } & $\begin{array}{c}\text { Treatment of } \\
\text { 1. RTH } \\
\text { 2. DTC }\end{array}$ & DTC follow-up \\
\hline Taniyama et al., 2001 & 46 & $\mathrm{~F}$ & FvPTC & $5 \mathrm{~mm}$ & THRB R2490 & $\begin{array}{l}\text { 1. Methimazole } \\
\text { 2. Subtotal thyroidectomy }\end{array}$ & NA \\
\hline Kim et al., 2010 & 38 & $\mathrm{~F}$ & PTC & $4 \mathrm{~mm}^{*}$ & THRB M310T & $\begin{array}{l}\text { 1. Levothyroxin } \\
\text { 2. Total thyroidectomy }\end{array}$ & NA \\
\hline Paragliola et al., 2011 & 48 & M & PTC & $24 \mathrm{~mm}$ & ND & $\begin{array}{l}\text { 1. Levothyroxin } \\
\text { 2. Total thyroidectomy }\end{array}$ & $\begin{array}{l}9.5 \text { years } \\
\text { In remission }\end{array}$ \\
\hline Paragliola et al., 2011 & 63 & M & PTC & $6 \mathrm{~mm}$ & THRB P453T & $\begin{array}{l}\text { 1. Levothyroxin } \\
\text { 2. Total thyroidectomy }\end{array}$ & $\begin{array}{l}5 \text { years } \\
\text { In remission }\end{array}$ \\
\hline Unluturk et al., 2013 & 33 & $\mathrm{~F}$ & PTC & $12 \mathrm{~mm}$ & ND & $\begin{array}{l}\text { 1. Levothyroxin } \\
\text { 2. Total thyroidectomy and radioiodine }\end{array}$ & $\begin{array}{l}1 \text { year } \\
\text { In remission }\end{array}$ \\
\hline Ramos-Prol et al., 2013 & 9 & $\mathrm{~F}$ & PTC & $24 \mathrm{~mm}^{*}$ & THRB R243W & $\begin{array}{l}\text { 1. TRIAC and levothyroxine } \\
\text { 2. Total thyroidectomy and radioiodine }\end{array}$ & $\begin{array}{l}2 \text { years } \\
\text { In remission }\end{array}$ \\
\hline Current case & 19 & $\mathrm{~F}$ & PTC & $4 \mathrm{~mm}$ & THRB R320C & $\begin{array}{l}\text { 1. Levothyroxin } \\
\text { 2. Total thyroidectomy and radioiodine }\end{array}$ & $\begin{array}{l}6 \text { years } \\
\text { In remission }\end{array}$ \\
\hline
\end{tabular}

RTH, Resistance to thyroid hormone syndrome; DTC, Differentiated thyroid cancer; FVPTC, Follicular variant of papillary thyroid carcinoma; PTC, Papillary thyroid carcinoma; ND, Not detected; NA, Not available; TRIAC, Triiodothyroacetic acid; ${ }^{*}$ multifocal tumors. 
by ultimately disrupting the hypothalamic-pituitary-thyroid axis tight regulation and TSH has long been known to increase adenylate cyclase activity leading to cAMP production and promoting cell growth (Dumont et al., 1992).

In the present case, an occult mPTC was found after thyroidectomy. The mPTC is a very common condition, being a frequent incidental finding in thyroid gland removal for other reasons, or in autopsy (Rosai et al., 2003). Although mPTC's usually show an indolent behavior, some (3-15\%) have the capability to spread to regional lymph nodes, and exceptionally metastasize to other organs (Simpson and Albores-Saavedra, 2007). Generally, mPTC developed in adolescence and young adulthood tend to present a growing rate similar to the thyroid gland, unless additional events occur and cause an increase in their growth rate (Rosai et al., 2003). It is well established that neck lymph node metastases are common in young individuals with papillary thyroid carcinoma and this fact contributes to the idea that thyroid cancer arising in a young patient is associated with a higher aggressiveness. However, most of the evidence in record concerns clinically evident papillary carcinomas. Regarding our case, we are referring an incidental papillary microcarcinoma, where it was demonstrated that age was not a significant factor affecting lymph node metastasis (Gulben et al., 2008). So, in addition to the continual thyrotrophic TSH stimulation we sought to identify what could have been an additional event(s) in our case. We evaluated the frequent oncogenic mutation in genes $N-R A S, H-R A S$, and $B R A F$ as potential relevant factors additionally to the TSH stimulation. We also analyzed TERT promoter mutations, a recent molecular change associated to thyroid tumors (Vinagre et al., 2013). Molecular analysis determined the presence of a BRAF mutation in the mPTC as well as in the respective metastases. Such finding fits with the papillary growth pattern, and is in agreement with the high frequency of BRAF mutations (43\%) we detected in a series of MPTC displaying papillary pattern (Trovisco et al., 2005). Conversely, BRAF mutation is associated with older patients, and tends to be rare in young adulthood PTC tumors (Trovisco et al., 2005; Fugazzola et al., 2006). Together, the young age of the patient and the high dissemination of the malignancy, lead us to suggest that increased TSH stimulation in a RTH background and oncogenic activation of BRAF could have served as (co) drivers. We are now aware that the management of the patient was not the most adequate as TSH levels still remained elevated although it is well established that maintenance of a suppression of TSH is challenging in this cases (Unluturk et al., 2013). The continual TSH stimulation as a consequence of the inadequate hormone replacement might have been a major tumor growth contributor. This stimulation probably causes the enlargement of the thyroid gland and the goitrogenic effect seen in patients with RTH syndrome and TSH-secreting pituitary adenomas. Cases of pituitary TSH-secreting adenomas in association with thyroid cancer have also been reported in the literature (for a review, please refer to reference Unluturk et al., 2013). These associations between TSH stimulation and thyroid cancer could also be supported by the studies referring the association between thyroid cancer and serum TSH concentration, and the possible role of TSH in the progression of differentiated thyroid cancer (for a thorough review, see reference Boelaert, 2009).
Additional interesting observation refers to the possible role of thyroid-stimulating antibodies simulating TSH effect in Grave's disease associated thyroid cancer. Although it remains a matter of controversy, studies have suggested an increase in aggressiveness (frequent distant metastases) of PTC and FTC in Grave's disease patients (Filetti et al., 1988; Yano et al., 2007).

Summing up, we speculate that the concurrence of TRHB mutation, high TSH levels and BRAF mutation might have acted toward the malignant transformation and the aggressiveness of the mPTC in the present case. All the other cases reviewed did not present tumor genotyping so we cannot infer about the $B R A F$ role in the other reported patients. Aggressive treatment can be an option to prevent tumor recurrence and persistence in the absence of an ideal TSH suppression, as was the case we report. Finally, we believe this subject will continue to be debatable, and new cases and novel presentations should be reported as so far the outcome of the reported cases have not been unfavorable and they will bring novel knowledge and information to this issue.

\section{ACKNOWLEDGMENTS}

The Portuguese Foundation for Science and Technology supported this study through a $\mathrm{PhD}$ grant to João Vinagre (Ref: SFRH/BD/81940/2011). Further funding was obtained from the project "Microenvironment, metabolism and cancer" that was partially supported by Programa Operacional Regional do Norte (ON.2 - O Novo Norte) under the Quadro de Referência Estratégico Nacional (QREN) and the Fundo Europeu de Desenvolvimento Regional (FEDER). IPATIMUP is an Associate Laboratory of the Portuguese Ministry of Science, Technology and Higher Education that is partially supported by the FCT.

\section{REFERENCES}

Beck-Peccoz, P., Persani, L., Calebiro, D., Bonomi, M., Mannavola, D., and Campi, I. (2006). Syndromes of hormone resistance in the hypothalamicpituitary-thyroid axis. Best Pract. Res. Clin. Endocrinol. Metab. 20, 529-546. doi: 10.1016/j.beem.2006.11.001

Boelaert, K. (2009). The association between serum TSH concentration and thyroid cancer. Endocr. Relat. Cancer 16, 1065-1072. doi: 10.1677/ERC09-0150

Burman, K. D., Djuh, Y. Y., Nicholson, D., Rhooms, P., Wartofsky, L., Fein, H. G., et al. (1992). Generalized thyroid hormone resistance: identification of an arginine to cystine mutation in codon 315 of the c-erb A beta thyroid hormone receptor. J. Endocrinol. Invest. 15, 573-579. doi: 10.1007/BF03344927

Dumont, J. E., Lamy, F., Roger, P., and Maenhaut, C. (1992). Physiological and pathological regulation of thyroid cell proliferation and differentiation by thyrotropin and other factors. Physiol. Rev. 72, 667-697.

Filetti, S., Belfiore, A., Amir, S. M., Daniels, G. H., Ippolito, O., Vigneri, R., et al. (1988). The role of thyroid-stimulating antibodies of Graves' disease in differentiated thyroid cancer. N. Engl. J. Med. 318, 753-759. doi: 10.1056/NEJM198803243181206

Fugazzola, L., Puxeddu, E., Avenia, N., Romei, C., Cirello, V., Cavaliere, A., et al. (2006). Correlation between B-RAFV600E mutation and clinico-pathologic parameters in papillary thyroid carcinoma: data from a multicentric Italian study and review of the literature. Endocr. Relat. Cancer 13, 455-464. doi: 10.1677/erc. 1.01086

Guigon, C. J., and Cheng, S. Y. (2009). Novel non-genomic signaling of thyroid hormone receptors in thyroid carcinogenesis. Mol. Cell Endocrinol. 308, 63-69. doi: 10.1016/j.mce.2009.01.007

Gulben, K., Berberoglu, U., Celen, O., and Mersin, H. H. (2008). Incidental papillary microcarcinoma of the thyroid-factors affecting lymph node metastasis. Langenbecks Arch. Surg. 393, 25-29. doi: 10.1007/s00423-007-0213-2 
Kim, H. K., Kim, D., Yoo, E. H., Lee, J. I., Jang, H. W., Tan, A. H., et al. (2010). A case of resistance to thyroid hormone with thyroid cancer. J. Korean Med. Sci. 25, 1368-1371. doi: 10.3346/jkms.2010.25.9.1368

Paragliola, R. M., Lovicu, R. M., Locantore, P., Senes, P., Concolino, P., Capoluongo, E., et al. (2011). Differentiated thyroid cancer in two patients with resistance to thyroid hormone. Thyroid 21, 793-797. doi: 10.1089/thy.2010.0233

Ramos-Prol, A., Antonia Perez-Lazaro, M., Isabel Del Olmo-Garcia, M., Leon-De Zayas, B., Moreno-Macian, F., Navas-De Solis, S., et al. (2013). Differentiated thyroid carcinoma in a girl with resistance to thyroid hormone management with triiodothyroacetic acid. J. Pediatr. Endocrinol. Metab. 26, 133-136. doi: 10.1515/jpem-2012-0230

Refetoff, S., Dewind, L. T., and Degroot, L. J. (1967). Familial syndrome combining deaf-mutism, stuppled epiphyses, goiter and abnormally high PBI: possible target organ refractoriness to thyroid hormone. J. Clin. Endocrinol. Metab. 27, 279-294. doi: 10.1210/jcem-27-2-279

Refetoff, S., and Dumitrescu, A. M. (2007). Syndromes of reduced sensitivity to thyroid hormone: genetic defects in hormone receptors, cell transporters and deiodination. Best. Pract. Res. Clin. Endocrinol. Metab. 21, 277-305. doi: 10.1016/j.beem.2007.03.005

Rocha, A. S., Marques, R., Bento, I., Soares, R., Magalhaes, J., De Castro, I. V., et al. (2007). Thyroid hormone receptor beta mutations in the 'hot-spot region' are rare events in thyroid carcinomas. J. Endocrinol. 192, 83-86. doi: 10.1677/JOE06-0009

Rosai, J., Livolsi, V. A., Sobrinho-Simoes, M., and Williams, E. D. (2003). Renaming papillary microcarcinoma of the thyroid gland: the Porto proposal. Int. J. Surg. Pathol. 11, 249-251. doi: 10.1177/106689690301100401

Sakurai, A., Takeda, K., Ain, K., Ceccarelli, P., Nakai, A., Seino, S., et al. (1989). Generalized resistance to thyroid hormone associated with a mutation in the ligand-binding domain of the human thyroid hormone receptor beta. Proc. Natl. Acad. Sci. U.S.A. 86, 8977-8981. doi: 10.1073/pnas.86.22.8977

Simpson, K. W., and Albores-Saavedra, J. (2007). Unusual findings in papillary thyroid microcarcinoma suggesting partial regression: a study of two cases. Ann. Diagn. Pathol. 11, 97-102. doi: 10.1016/j.anndiagpath.2006.03.008

Taniyama, M., Ishikawa, N., Momotani, N., Ito, K., and Ban, Y. (2001). Toxic multinodular goitre in a patient with generalized resistance to thyroid hormone who harbours the R429Q mutation in the thyroid hormone receptor beta gene. Clin. Endocrinol. (Oxf.) 54, 121-124. doi: 10.1046/j.1365-2265.2001.01033.x
Trovisco, V., Soares, P., Preto, A., De Castro, I. V., Lima, J., Castro, P., et al. (2005). Type and prevalence of BRAF mutations are closely associated with papillary thyroid carcinoma histotype and patients' age but not with tumour aggressiveness. Virchows Arch. 446, 589-595. doi: 10.1007/s00428-0051236-0

Unluturk, U., Sriphrapradang, C., Erdogan, M. F., Emral, R., Guldiken, S., Refetoff, S., et al. (2013). Management of differentiated thyroid cancer in the presence of resistance to thyroid hormone and TSH-secreting adenomas: a report of four cases and review of the literature. J. Clin. Endocrinol. Metab. 98, 2210-2217. doi: 10.1210/jc.2012-4142

Vinagre, J., Almeida, A., Populo, H., Batista, R., Lyra, J., Pinto, V., et al. (2013). Frequency of TERT promoter mutations in human cancers. Nat. Commun. 4, 2185. doi: 10.1038/ncomms3185

Yano, Y., Shibuya, H., Kitagawa, W., Nagahama, M., Sugino, K., and Ito, K. (2007). Recent outcome of Graves' disease patients with papillary thyroid cancer. Eur. J. Endocrinol. 157, 325-329. doi: 10.1530/EJE-07-0136

Yen, P. M. (2001). Physiological and molecular basis of thyroid hormone action. Physiol. Rev. 81, 1097-1142.

Conflict of Interest Statement: The authors declare that the research was conducted in the absence of any commercial or financial relationships that could be construed as a potential conflict of interest.

Received: 18 July 2014; accepted: 12 August 2014; published online: 02 September 2014. Citation: Vinagre J, Borges F, Costa A, Alvelos MI, Mazeto G, Sobrinho-Simões M and Soares $P$ (2014) Differentiated thyroid cancer in patients with resistance to thyroid hormone syndrome. A novel case and a review of the literature. Front. Mol. Biosci. 1:10. doi: 10.3389/fmolb.2014.00010

This article was submitted to Molecular Diagnostics, a section of the journal Frontiers in Molecular Biosciences.

Copyright (c) 2014 Vinagre, Borges, Costa, Alvelos, Mazeto, Sobrinho-Simões and Soares. This is an open-access article distributed under the terms of the Creative Commons Attribution License (CC BY). The use, distribution or reproduction in other forums is permitted, provided the original author(s) or licensor are credited and that the original publication in this journal is cited, in accordance with accepted academic practice. No use, distribution or reproduction is permitted which does not comply with these terms. 